\section{Commentary: First master the fundamentals}

\author{
Christopher E. Mascio, MD, and Vinay Badhwar, MD
}

Woo and colleagues ${ }^{1}$ present a video demonstrating relationships of circumferential angles, cusp fusion length, and commissural fusion height in normal aortic valves, type 1 bicuspid aortic valves (BAV), and type $0 \mathrm{BAV}$, as classified by Sievers and Schmidtke. ${ }^{2}$ Although actual presentation of pathology is not an evolving continuum in a single patient, this video presents this information in sequential fashion commencing with the $120^{\circ}$ commissural angle, $20 \mathrm{~mm}$ commissural height, and $0 \mathrm{~mm}$ fusion length of a normal tricuspid aortic valve, and concludes with the $180^{\circ}$ commissural angle, $0 \mathrm{~mm}$ commissural height, and $20 \mathrm{~mm}$ fusion length of a type $0 \mathrm{BAV}$. Much has been discovered about the best therapies for BAV over the past decade, and the treatment algorithm today is quite sophisticated. As with any complex task, mastering the fundamentals is critical to success. This video provides a visual representation of the various anatomic phenotypes encountered by the cardiovascular surgeon, and in turn, engenders an essential understanding critical for proper treatment.

Pathologies related to BAV are among the most common congenital cardiac anomalies, with an incidence of up to $2 \%$ in the general population. ${ }^{3,4}$ It has also been associated with dilatation of the ascending aorta and subsequent aneurysm and/or dissection formation. ${ }^{5}$ This information, along with advanced surgical techniques and a better understanding of the structure and function of the aortic valve, prompted Sievers and Schmidtke ${ }^{2}$ to describe a classification system for BAV. He described 3 types: type 0 (0 raphe), type 1 (1 raphe), and type 2 ( 2 raphes). As has been illustrated, these different BAV entities were not all best treated

From the Department of Cardiovascular and Thoracic Surgery, West Virginia University, Morgantown, WVa.

Disclosures: The authors reported no conflicts of interest.

The Journal policy requires editors and reviewers to disclose conflicts of interest and to decline handling or reviewing manuscripts for which they may have a conflict of interest. The editors and reviewers of this article have no conflicts of interest.

Received for publication July 3, 2021; revisions received July 3, 2021; accepted for publication July 7, 2021; available ahead of print July 10, 2021.

Address for reprints: Vinay Badhwar, MD, Department of Cardiovascular and Thoracic Surgery, West Virginia University, Morgantown, WV 26506 (E-mail: vinay.badhwar@wvumedicine.org).

JTCVS Techniques 2021;9:46-7

2666-2507

Copyright (C) 2021 The Author(s). Published by Elsevier Inc. on behalf of The American Association for Thoracic Surgery. This is an open access article under the CC BY license (http://creativecommons.org/licenses/by/4.0/).

https://doi.org/10.1016/j.xjtc.2021.07.003

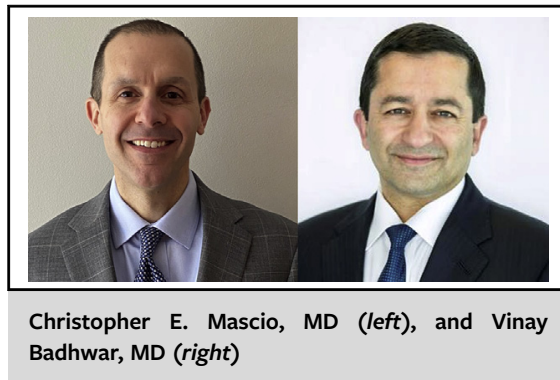

CENTRAL MESSAGE

BAV morphology and the best surgical therapy for each

phenotype is complex and

evolving. This video provides an

important educational review of

the various BAV types.

with the same surgical therapy; for example, the Ross procedure and valve replacement in type $0 \mathrm{BAV}$ is more challenging, requiring a circular proximal suture line and more attention to placement of the coronary buttons. ${ }^{2}$

This growing knowledge of BAV has led to more elaborate discussion about interventions on this disease entity. Jahanyar and colleagues ${ }^{6}$ describe the varying surgical approaches recommended for different phenotypes. Their repair-oriented classification includes symmetric, asymmetric, and very asymmetric types. The repairs are quite different for each type and range from cusp plication and $180^{\circ}$ repair (symmetric) to commissurotomy with commissure resuspension and patch reconstruction (very asymmetric). Similarly, de Kerchove and colleagues ${ }^{7}$ describe symmetric (type A) to asymmetric (type C) phenotypes, and propose different repairs based on certain anatomic characteristics, including commissure orientation, length of fusion, and nonfunctional commissure height. Now, many patients with insufficiency due to BAV can undergo repair with adjunctive remodeling ring annuloplasty, and via a less-invasive manner. ${ }^{8}$

We commend the authors on this succinct and elegantly presented introduction to BAV pathology. This video could be the first step of creation of an important resource for trainees and early career cardiovascular surgeons.

\section{References}

1. Woo YJ, Paulsen MJ, de Kerchove L, Zhu Y. Videographic conceptual dynamic representation of bicuspid aortic valve anatomic configurations and structural inter-relationships. J Thorac Cardiovasc Surg Tech. 2021;9:44-5. 
2. Sievers HH, Schmidtke C. A classification system for the bicuspid aortic valve from 304 surgical specimens. J Thorac Cardiovasc Surg. 2007;133:1226-33.

3. Ward C. Clinical significance of the bicuspid aortic valve. Heart. 2000;83:81-5.

4. Gray GW, Salisbury DA, Gulino AM. Echocardiographic and color flow Doppler findings in military pilot applicants. Aviat Space Environ Med. 1995;66:32-4.

5. Nistri S, Sorbo MD, MarinM, Palisi M, Scognamiglio R, Thiene G. Aortic root dilatation in young men with normally functioning bicuspid aortic valves. Heart. 1999;82:19-22.
6. Jahanyar J, El Khoury G, de Kerchove L. Commissural geometry and cusp fusion insights to guide bicuspid aortic valve repair. J Thorac Cardiovasc Tech. 2021;7: $83-92$.

7. de Kerchove L, Mastrobuoni S, Froede L, Tamer S, Boodhwani M, van Dyck M, et al. Variability of repairable bicuspid aortic valve phenotypes: toward an anatomical and repair-oriented classification. Eur J Cardiothorac Surg. 2019:56:351-9.

8. Badhwar V, Murashita T, Wei LM, Rankin JS. Minimally invasive bicuspid aortic valve repair using geometric ring annuloplasty. Ann Thorac Surg. 2020;109:e5-7. 